\title{
SIMULATION OF THE POTENTIAL AND ELECTRIC FIELD DISTRIBUTION ON HIGH VOLTAGE INSULATOR USING THE FINITE ELEMENT METHOD
}

\author{
Hani BENGUESMIA ${ }^{1,2}$, Nassima M'ZIOU ${ }^{1,3}$, Ahmed BOUBAKEUR ${ }^{4}$ \\ ${ }^{1}$ Laboratoire de recherche (LI3CUB), Biskra University, BP 145 RP, 07000, Biskra, Alegria. \\ ${ }^{2}$ Department of Electrical Engineering, Faculty of Technology, M'sila University, B.P. 166, 28000, M'sila, \\ Algeria. \\ e-mail: hanibenguesmia16@gmail.com \\ ${ }^{3}$ Department of Electrical Engineering, Faculty of Engineer Sciences, Boumerdes University, Avenue de \\ l'Indépendance, 35000, Boumerdes, Algeria. \\ ${ }^{4}$ Laboratoire de Recherche en Electrotechnique (L.R.E). Ecole Nationale Polytechnique, Algiers, Algeria.

\section{Abstract} \\ The knowledge of the distribution of the electric field within and around high voltage equipment is a \\ crucial aspect of the design, exploitation and performance of high voltage insulators. It could be useful for the \\ detection of defects in insulators. The objective of this study is predicting the behavior of polluted insulator \\ under $\mathrm{AC}$ voltage. For thus, the distribution of the potential and the electric field along high voltage insulator \\ is investigated using a numerical method. The commercial Comsol Multiphysics proved to be one of the best \\ software used in 2D modeling. The potential and the electric field distributions along this insulator are \\ simulated under various conditions: the two cases: clean and polluted insulators and applying different \\ conductivity values. We used electrostatic $2 \mathrm{D}$ simulations in the AC/DC module. The results are auspicious \\ and promising.
}

Keywords: Simulation, MEF, high voltage, electrical potential, electric field.

\section{INTRODUCTION}

The importance of research on insulator pollution has increased considerably with the increase in transmission line voltage [1-2]. Indeed, The performance of insulators in a polluted environment is one of the guiding factors in the insulation coordination of high voltage transmission lines [3]. Transmission lines and high voltage transformer used in electric power delivery are subject to various constraints such as insulator pollutions, which is of prime interest regarding power quality issues and reliability [4].

Flashover pollution caused by the insulators used in high voltage transmission is one of the most significant problems for power transmission. It is a problem due to several reasons like difficulties in modeling the complex shape (form) of the insulator, different pollution density at different regions, nonhomogenous distribution on the pollution area of the insulator, and the unknown effect of humidity on the pollution [5-6]. Cap and pin insulators are widely used in power transmission and distribution lines for a long time. Electrical insulators frame an essential segment of high voltage electrical systems, such as sub-stations and transmission and distribution lines which are used to support the line conductors to free them electrically from each other [7]. Insulator pollution phenomena are considered as a continuous or intermittent accumulation (deposition) of impurities coming from various sources. It can result from a cloud of smokes (industrial and urban pollution) [8], or small particles of salt in coastal regions (marine pollution)[9-10], even fine particles are coming from a sandstorm in the desert regions (desert pollution) [11-14].

Recently, the numerical models based on the finite element method [15-16] give better results in the modeling of the flashover phenomenon of the insulators polluted compared to the static and dynamic models. Consequently, it is essential to model the electric fields and potentials to analysis the characteristics and the behavior of the polluted insulators. The electric field and potential distribution can be estimated using various numerical techniques, such as Charge Simulation Method (CSM), Finite Difference Method (FDM), Boundary Element Method (BEM) and Finite Element Method (FEM). In the field of high voltage transmission line applications, the published results of the numerical simulation of the potential distribution and the electric field of some studies are all for simple geometries [17-22]. A numerical simulation is an approach that gives researchers the possibility to analyze the behavior of several phenomena which, because of their complexity, are beyond the scope of classical calculus [16]. For this reason, COMSOL Multiphysics can serve as a powerful and interactive way to solve complex 
problems using the finite element method. COMSOL Multiphysics is a widely used tool in various fields of scientific research. It amply facilitates the modeling steps.

The Finite Element Method (FEM) is most wellsituated to calculate the electric field and potential distribution in high voltage insulator because it is one of the more successful numerical methods to solve electrostatic problems (using the discretization of the domain)[23]. Hence, it is a flexible method and leads to relatively simple techniques allowing to estima te the fields at the surface of the electrode thin and highly curved with various dielectric materials, which is well adapted to problems of complicated geometry [24-27].

In this article, the two dimensions of finite element method (FEM) developed by real geometrical dimension, and it is implemented to calculate the electric field and the potential distribution of the insulator. The primary objective is to study the electrical field and potential distribution of clean and dry insulator under discontinuous uniformly polluted. Electric field and potential distribution along a cap and pin insulator (1512L) was calculated in COMSOL Multiphysics. Electric currents formulation was used to study the effect of pollution conductivity on the electric field distribution. The thickness of pollution layer was fixed (L1: Level of discontinuous pollution). Various conductivities employed to investigate the effect of pollution on electric field and potential distribution.

The study described below was carried out by the COMSOL Multiphysics software. This article is organized as a development of the FEM model, solving the FEM(discretization), the discussion of the results of electric field and potential distribution which considers the real shape of an insulator and adds different conductivities and applied voltage of the line has been computed. The rest of the paper is organized as follows. Section 2, provides a brief description of the real model of insulator, parameters and material properties in the Finite Element Method (FEM). In Section 3, finite element methods of analysis to estimate the electric field and potential distribution is presented. By section 4 , we give and we discuss the different results obtained by using Comsol Multiphysics simulation. Finally, conclusions of the present work are drawn.

\section{METHOD OF THE SIMULATION}

COMSOL Multiphysics is a powerful interactive environment for modeling and solving all kinds of scientific and engineering problems based on partial differential equations (PDEs). With this software, we can easily extend conventional models for one type of physics model into multiphysics models that solve coupled physics phenomena. It is possible to build models by defining the physical quantities, such as material properties, loads, constraints, rather than by defining the underlying equations. You can always apply these variables, expressions, or numbers directly to solid domains, boundaries, edges, and points independently of the computational mesh. In our work, each material (glass, portland, air, and cement) (fig. 2 (a)) define by its permittivity and conductivity, (table 2) and we pass to the boundary conditions. COMSOL then internally compiles a set of PDEs representing the entire model. You access the power of COMSOL through a flexible graphical user interface, or by script programming in the COMSOL Script language.

Cap and pin insulators have four major components. They consist of an insulating block carrying to its upper part a cap sealed out of malleable pig iron and inside a steel stem, with grooves and whose conical head is also sealed in glass. The lower end of this stem is round and has dimensions wanted to penetrate in the cap of the following element and to be maintained by a pin there.

In this part, an insulator made of the glass material is considered for the simulation dimensions of the $220 \mathrm{kV}$ insulation. Figure and table 1 give the real parameters of the insulator used in the simulation. The FEM model of the real insulator is depicted in figure 2 .

We examine the electric field and potential distribution of glass insulator in two different surface conditions. The first, in the clean model and the second, under discontinuous pollution for different conductivities. The properties of the materials of the various domains of the insulator (cap, pin, glass..etc.) are shown in table 2 .

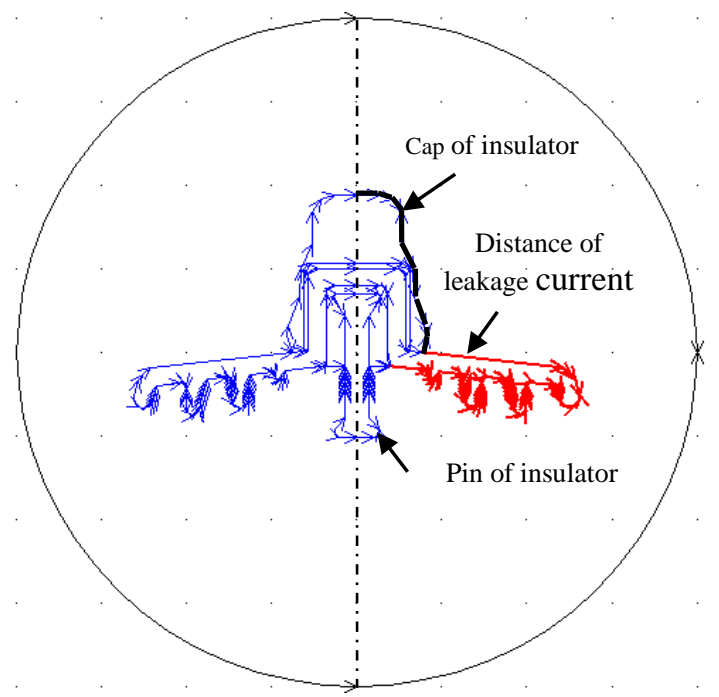

Fig. 1. Parameters of cap and pin insulator 1512L

Table 1. Geometrical parameter of cap and pin 1512L

insulator

\begin{tabular}{|c|c|}
\hline Parameters & Size (mm) \\
\hline Distance of leakage current & 292 \\
\hline Cap of insulator & 244 \\
\hline Pin of insulator & 125 \\
\hline
\end{tabular}




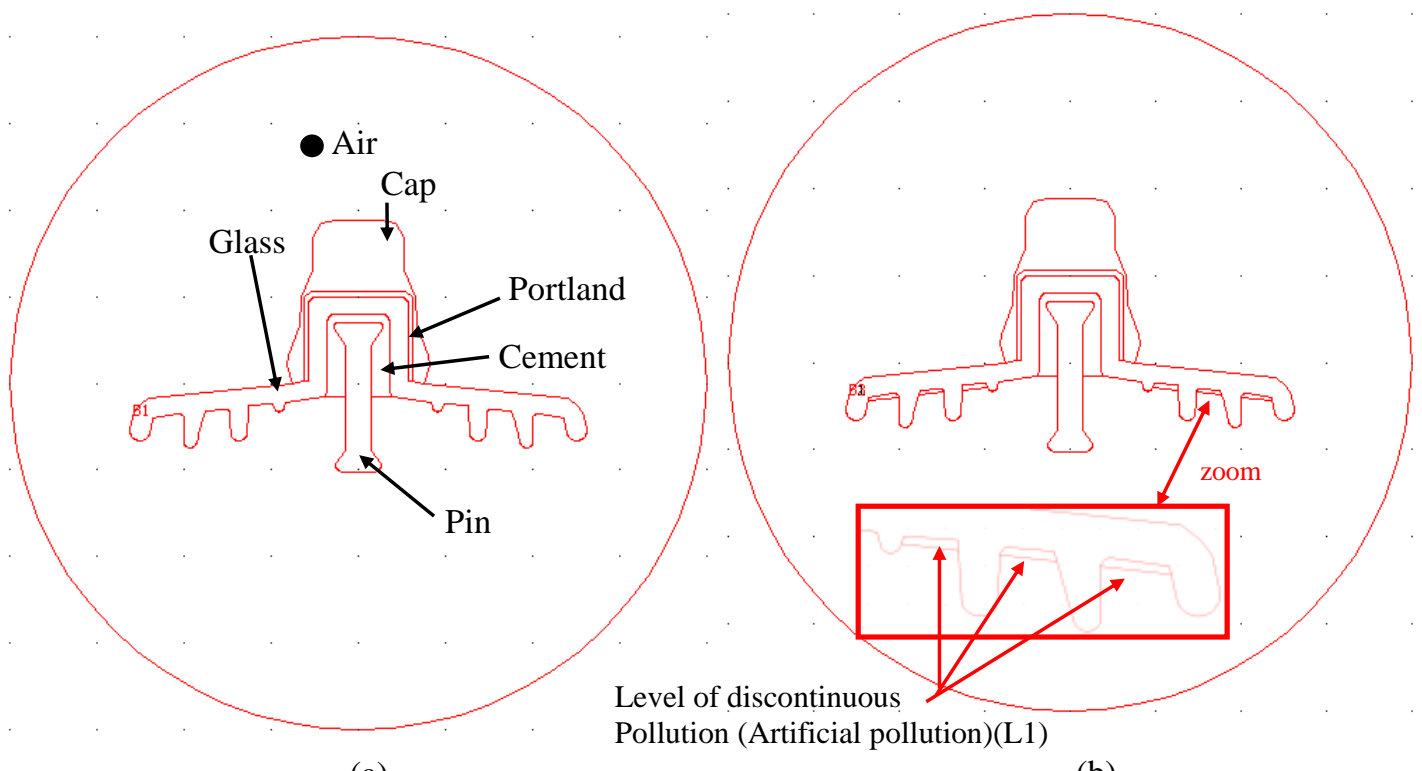

(a)

(b)

Fig. 2. FEM model in the software of $220 \mathrm{kV}$ insulator

(a) Clean model, (b) Discontinuous uniformly polluted model

Table 2. Material properties of FEM model of cap and pin 1512L insulator

\begin{tabular}{|c|c|c|c|c|c|}
\hline Properties & $\begin{array}{c}\text { Cap } \\
\text { pin }\end{array}$ & Glass & $\begin{array}{c}\text { Portland } \\
\& \\
\text { Cement }\end{array}$ & Air & $\begin{array}{c}\text { Artificial } \\
\text { pollution }\end{array}$ \\
\hline Relative permittivity $\left(\varepsilon_{r}\right)$ & $10^{6}$ & 6 & 5 & 1.0005 & 80 \\
\hline Conductivities $(\mu \mathrm{s} / \mathrm{cm})$ & $10^{6}$ & $1 . \mathrm{e}^{-12}$ & $1 . \mathrm{e}^{-12}$ & $1 . \mathrm{e}^{-14}$ & $0,70,700,1200,3000$ \\
\hline
\end{tabular}

\section{MATHEMATICAL MODEL}

Electrostatic problems consider the behavior of electric field intensity: $E$, and electric flux density (alternatively electric displacement) : $D$. There are two conditions that these quantities must obey. The first condition is the differential form of Gauss Law, which says that the flux out of any closed volume is equal to the charge contained within the volume [28-29]. The basic equations used to calculate the potential (electric field) are Maxwell's equations:

For the electrostatic model, the following equations are used:

$$
\begin{aligned}
& \operatorname{div} \vec{D}=\rho \\
& \vec{D}=\varepsilon \vec{E} \\
& \vec{E}=-\overrightarrow{\operatorname{grad}} V
\end{aligned}
$$

The combination of these three equations gives:

$\operatorname{div} \varepsilon(-\overrightarrow{\operatorname{grad}} V)=\rho$

$\operatorname{div} \varepsilon \overrightarrow{\operatorname{grad}} V=\rho$

This expression $(4,5)$ is called the Poisson equation. So the Laplace's equation can be obtained by making space charge $\rho=0$.

In our case, in high-voltage equipment, space charges are not present or negligible $(\rho=0)$ and therefore the equation to be solved for the dielectric media is [30-31]:

$\operatorname{div} \varepsilon(-\overrightarrow{\operatorname{grad}} V)=0$

The program solves (6) for voltage (potential) distribution $V$ over a user-defined domain with user-defined sources and boundary conditions.

For conductive media in stationary mode, it comes, since $\operatorname{div} \vec{j}=0$ et $\vec{j}=\sigma \vec{E}$ :

$\operatorname{div}(\sigma(-\overrightarrow{\operatorname{grad}} V))=0$

The equation of the place in Cartesian coordinates is:

$$
\operatorname{div} \overrightarrow{\operatorname{grad}}=\frac{\partial^{2} V}{\partial^{2} x}+\frac{\partial^{2} V}{\partial^{2} y}+\frac{\partial^{2} V}{\partial^{2} z}
$$

The calculation software determines the electrical potential to obtain the field distribution by solving the following partial differential equation for two dimensions [20]. 


$$
-\operatorname{div} \varepsilon \overrightarrow{\operatorname{grad}} V-\operatorname{div} \sigma \overrightarrow{\operatorname{grad}} V=0
$$

For resolution steps in Comsol Multiphysics can be summarized in the following four successive steps:

- The first step is to introduce the twodimensional (2D) geometry of the 1512L insulator to the Comsol (software).

- The second step concerns the definition of the electrical properties of the materials used. It consists of defining the relative permittivities $\varepsilon$ and the conductivities $\sigma$ for each part of the insulator. Also, it is necessary to define the boundary conditions which are translated into the potential imposed on each electrode (Dirichlet conditions).

- The third step is devoted to solving the problem by applying the numerical method and the construction of the system of equations (-div \& $\overrightarrow{g r a d} V-d i v \sigma \overrightarrow{g r a d} V=0)$, and this by introducing the factors of each part of the equation.

- The final step is to solve the problem and display the simulation results as the potential and electric field distribution.

The algorithm simulation computer flowchart for COMSOL is illustrated by figure 3 .

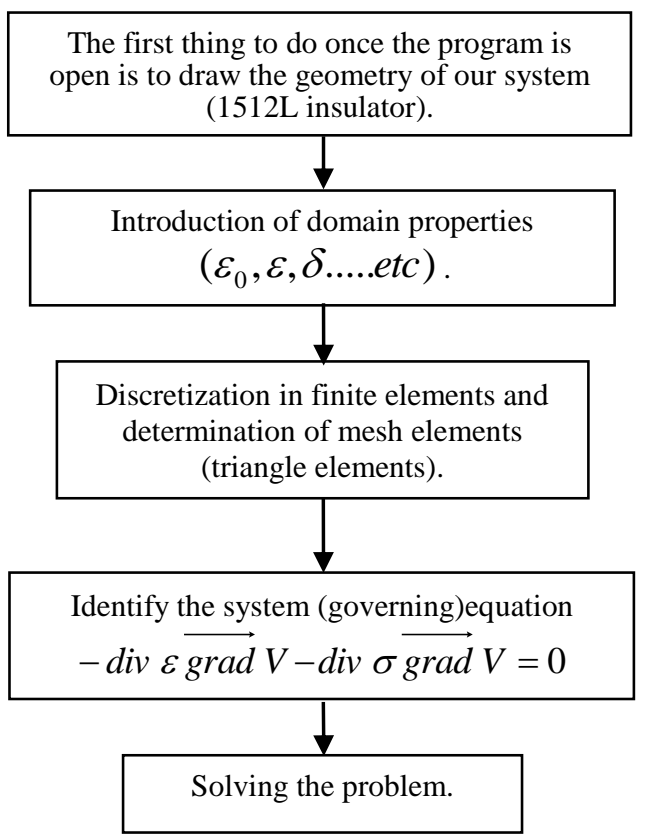

Fig. 3. Resolution Steps by COMSOL Multiphysics

\section{RESULTS AND DISCUSSION}

Electric field distribution and voltage distribution mainly depends on applied voltage, properties of materials used in insulator and surrounding or environmental condition.

Pollution effect plays an important role in determining the potential distribution and the electric field along the insulator. To demostrate this effect, several values of the conductivities of the pollution layer were used. The clean case was also introduced for reference, we suppose that the Finite Elements Method was best suited to the constraints imposed by the problem. Also, this method has been successfully applied in calculating the electrical field and potential distribution around the insulators. We introduced presented our model with all its specifications in table 2 to this software. Due to the complexity of our real model, we have drawn the model in the FEMM software; then we call the model in the software comsol, we followed all the steps as shown by figure 3 . We fixed the applied voltage of the active electrode with $30 \mathrm{kV}$

The density of the mesh is higher in the critical areas (regions) of the insulator, where higher precision is necessary. The mesh of the studied field in 2D was refined at the insulator, metallic pieces to get a better precision, the conductivities used for this study are chosen according to the study carried by [1].

Numerical results for different meshing presented by figure 4 . In fact, the type of the mesh has been changed based on the elements number. For thus, two meshes have been tested. The first case corresponds to a coarse mesh composed of 15668 elements (see figure 4(a)). The second case corresponds to 62672 elements after refining (see figure 4(b)). The corresponding time calculation and the number of nodes and all characteristics of meshing are presented in table 3 .

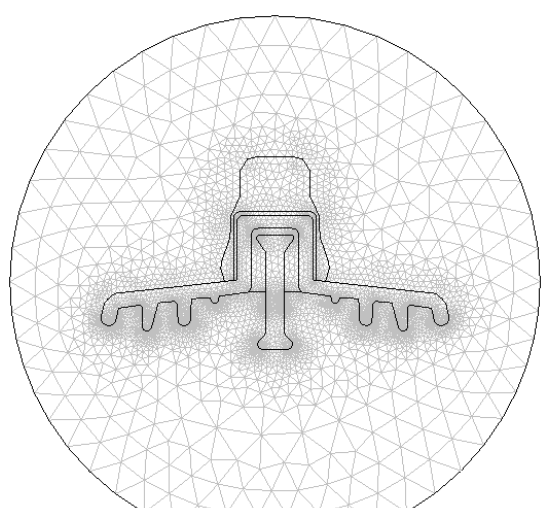

(a) 15668 elements

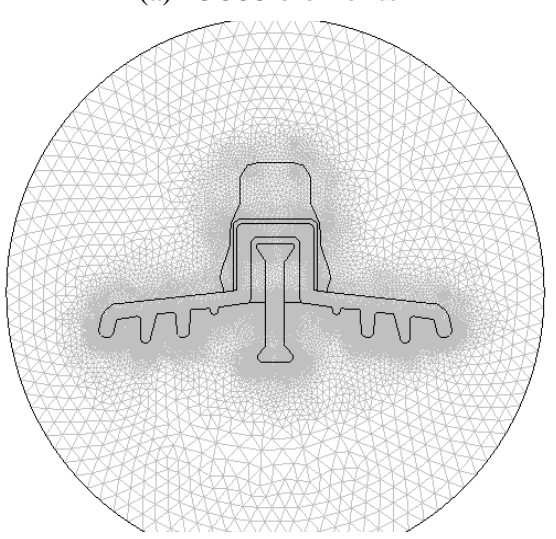

(b) 62672 elements

Fig. 4. Discretization in finite elements and determination of mesh elements of the insulator $1512 \mathrm{~L}$ 
Table 3. Characteristic of the meshing

\begin{tabular}{|c|c|c|c|c|c|c|c|c|}
\hline \multicolumn{2}{|l|}{} & $\begin{array}{c}\text { Number } \\
\text { of degrees } \\
\text { of } \\
\text { freedom }\end{array}$ & $\begin{array}{c}\text { Number } \\
\text { of } \\
\text { nodes }\end{array}$ & $\begin{array}{c}\text { Number } \\
\text { of } \\
\text { boundary } \\
\text { elements }\end{array}$ & $\begin{array}{c}\text { Vertex } \\
\text { elements }\end{array}$ & $\begin{array}{c}\text { Minimum } \\
\text { element } \\
\text { quality }\end{array}$ & $\begin{array}{c}\text { Surface } \\
\text { ratio of } \\
\text { the } \\
\text { element }\end{array}$ & $\begin{array}{c}\text { Time } \\
\text { calculation } \\
(S)\end{array}$ \\
\hline $\begin{array}{c}\text { Number of } \\
\text { elements }\end{array}$ & 15668 & 62774 & 7860 & 912 & 208 & 0.714 & $3.41 \mathrm{e}^{-6}$ & 3.025 \\
\hline $\begin{array}{c}\text { Number of } \\
\text { elements after the } \\
\text { first refining }\end{array}$ & 62672 & 250890 & 31387 & 1824 & 208 & 0.714 & $3.41 \mathrm{e}^{-6}$ & 7.285 \\
\hline
\end{tabular}

\subsection{Electric potential distribution}

This first part is devoted to the study of the distribution of the electrical potential on the insulator $1512 \mathrm{~L}$.

\subsubsection{Influence of the conductivities}

We are determining the potential distribution of the $1512 \mathrm{~L}$ using. The following values of the conductivities $\sigma=0,70,700,1200,3000 \mu \mathrm{S} / \mathrm{cm}$.

The applied voltage of the line was fixed to $30 \mathrm{kV}$. It helps to simulate the behavior of the insulators of high voltage $(220 \mathrm{kV})$.

Figures 5,6 and 7 show the potential and electrical potential distribution for different conductivities and the variation of the potential along the distance of leakage current for respectively different conductivities.

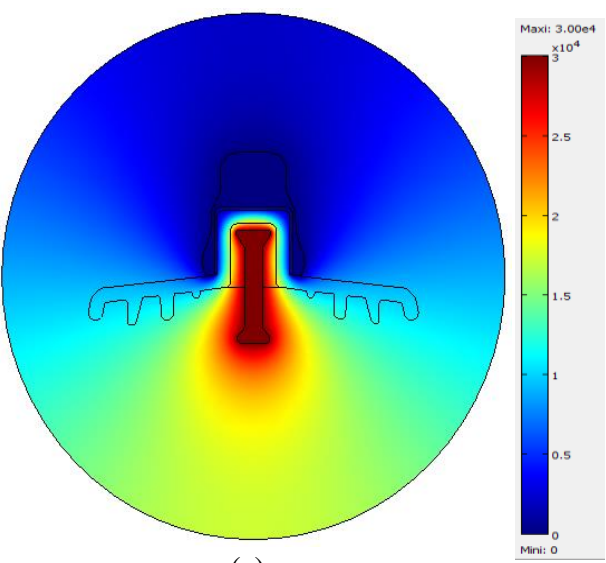

(a)

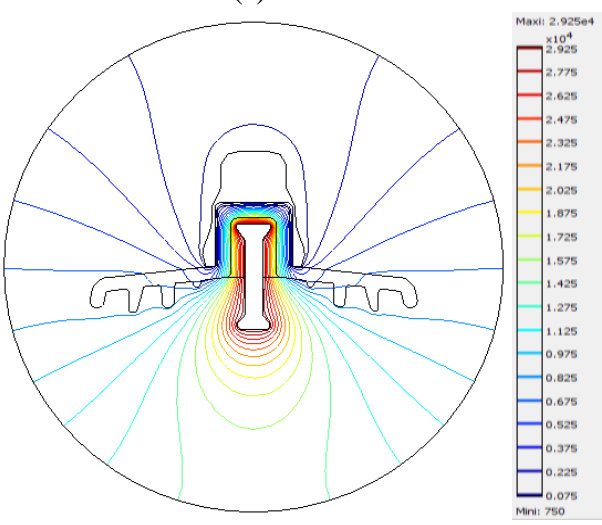

(b)

Fig. 5. Potential distribution and equipotential lines (clean model)

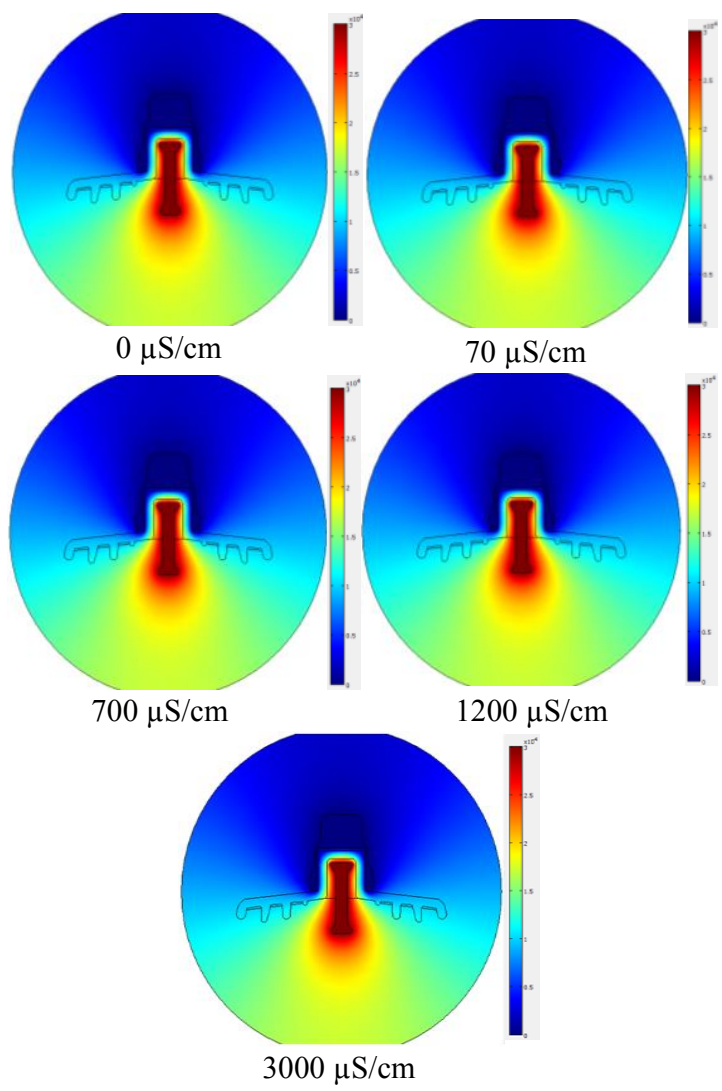

Fig. 6. Electrical potential distribution for different conductivities

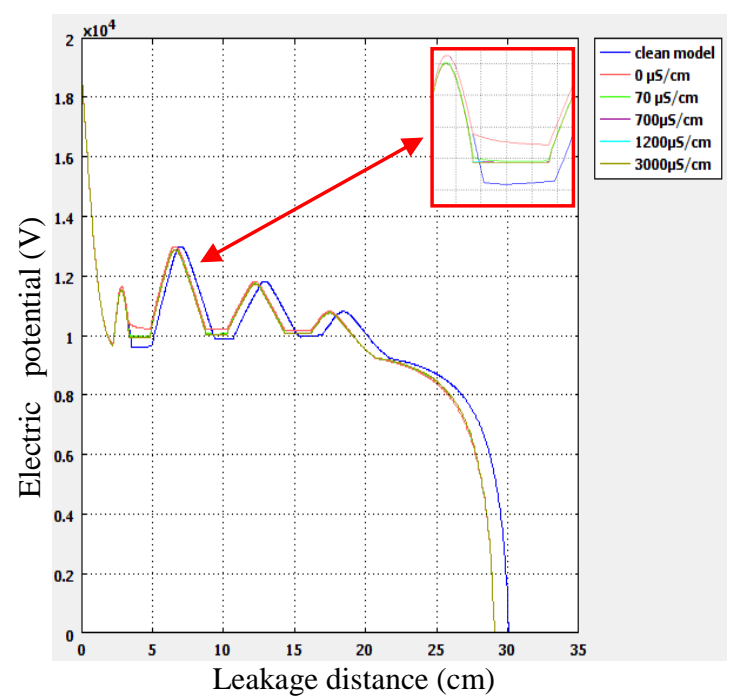

Fig. 7. Electric potential-leakage distance for different conductivities 
The potential is significant to the high voltage electrode and then decreases as one moves away from the ground electrode. In the case of the clean and polluted model, $30 \mathrm{kV}$ is the maximum value of the voltage, shown around the active electrode, and then decreases linearly as it moves away from this electrode to the grounding electrode where the potential is cancelled. For a $\sigma=0,70,700,1200$, $3000 \mu \mathrm{S} / \mathrm{cm}$ the curves of the potential are confused. In the clean case, the curves of the potential are closer to that of $\sigma=0,70,700,1200$, $3000 \mu \mathrm{S} / \mathrm{cm}$. We note that the variation of the conductivity of the polluted layer has no effect on the potential along the leakage distance of the insulator. No difference was observed comparing the potential obtained for two cases: cleaned and polluted insulator.

\subsubsection{Influence of the applied voltage of the line}

Figure 8 presents the distribution of potential in function of the leakage distance for different applied voltage. It shows that only the values of applied voltage change but the shape remains is the same. The cap and the pin being the metallic parts. The voltage to their levels remains constant; they are the parts equipotential (active electrode (HV) and ground electrode). The variation of the potential depending on the leakage distance for different applied voltage.

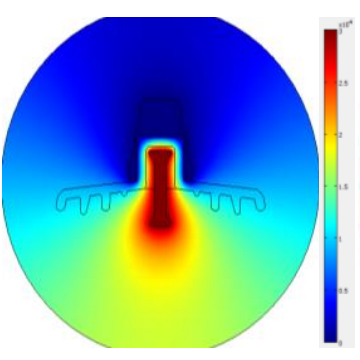

$30 \mathrm{kV}$

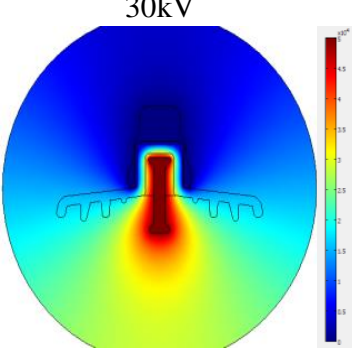

$50 \mathrm{kV}$

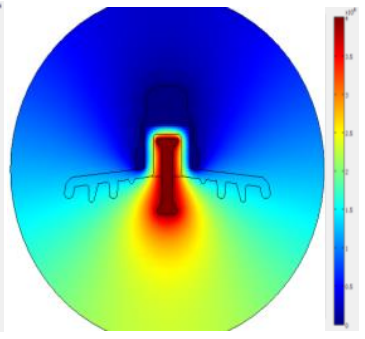

$40 \mathrm{kV}$

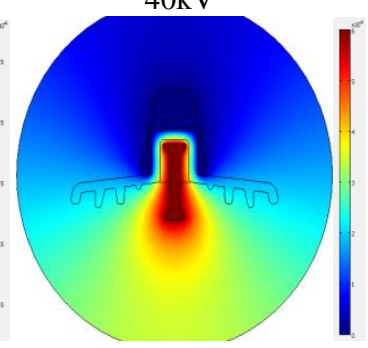

$60 \mathrm{kV}$
Fig. 8. Electrical potential distribution for different applied voltage of the line

Four levels of applied voltage were considered (see figure 9). We found that in function of the applied voltage of the line, the potential is distributed equitably along the leakage distance. The three curves are passing equally by three regions where the potential remains constant. It has to do with the metallic parts of the insulator.

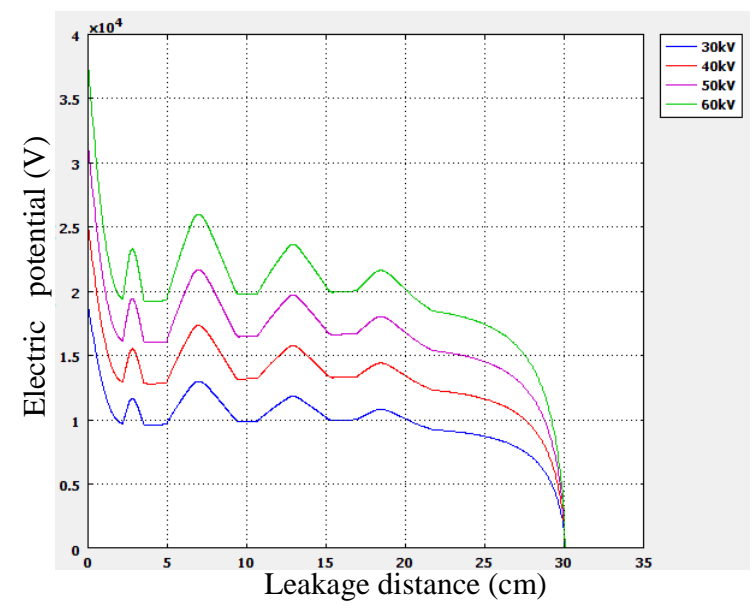

Fig. 9. Electric potential-leakage distance for different applied voltage of the line

\subsection{Electric field distribution}

The electric field have been investigated by many researchers $[2,4,19-23,25-27,29-31,35]$. In the case of the clean model, (see figure 10).

We have some findings:

Within the two electrodes (active and ground electrodes), the electric field is practically zero, because the two electrodes are conductive, the vectors of the electrical fields emerge from the activated electrode to ground electrode. The vectors as demostrated by figure 10 are a tangent; we can note that the electric field is more significant with the internal dimensions of the electrodes.

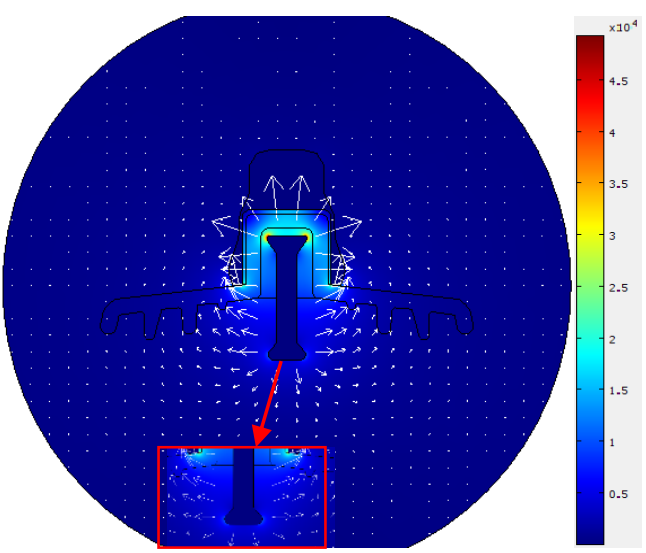

Fig. 10. Electrical (electric) field distribution for a clean model

\subsubsection{Influence of the conductivities}

For a constant voltage of $30 \mathrm{kV}$, figure 11 displays the variations of the intensity of electric field along of the leakage distance of the insulator for different conductivities. The intensity electric field is very high notably when the model is polluted, in the cap of insulator (ground). The electric field is not affected by the conditions of the surface, (polluted or clean) of the insulator.

In the clean layers on the surface of the insulator, the electric field is more intense, which 
explains experimentally, the appearance of the electric arcs at the levels of the clean layers before the flashover of the insulator. Indeed, the electric arcs were observed in experimental studies by many researchers [4,32-35]. The electric field lines diverge from the active electrode (oriented from the $\mathrm{HV}$ electrode to the ends of the insulator and converge towards the ground electrode), the system becomes less rigid and the conductivity of the surface of the insulator increases. Near of the active electrode, the electric field is intense and decreases as it moves away from the active electrode and closer to the ground electrode. Also, the electric field lines diverge (from the HV (active) electrode to the ground electrode). In the near area of the active electrode, the electric field is important (relevant), and almost zero in the clean zones illustrated in (figure 11(a)). Figure 11 (b) presented the logarithmic scale shows that in the dielectric material, the electric fields are never canceled, but takes values close to zero, (field does not disappear in the insulator but gives a very low value).

Figure 11 (a) explains the distribution of the electric field on the leakage distance for different conductivities; we notice that the electric field is prominent near the active electrode and takes the value almost zero in clean areas. (Simple scale).

We also note a slight decrease in the line of leakage distance in the polluted case compared to clean case (clean model) due to the creation of the polluting layer in the surface of the insulator. (Figure 11 (b)) is very important, says the electric field distribution in a logarithmic scale, which shows that for clean areas the electric field never cancels but takes from near zero. In this case, the interest of the logarithmic scale to explain well that in the dielectric materials the electric field never annuls, but takes values near zero.

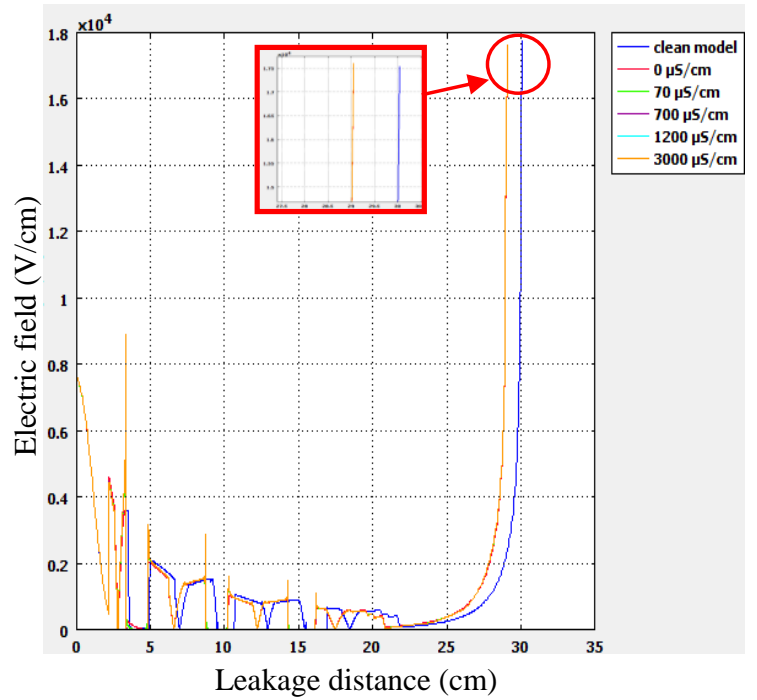

(a) Simple scale

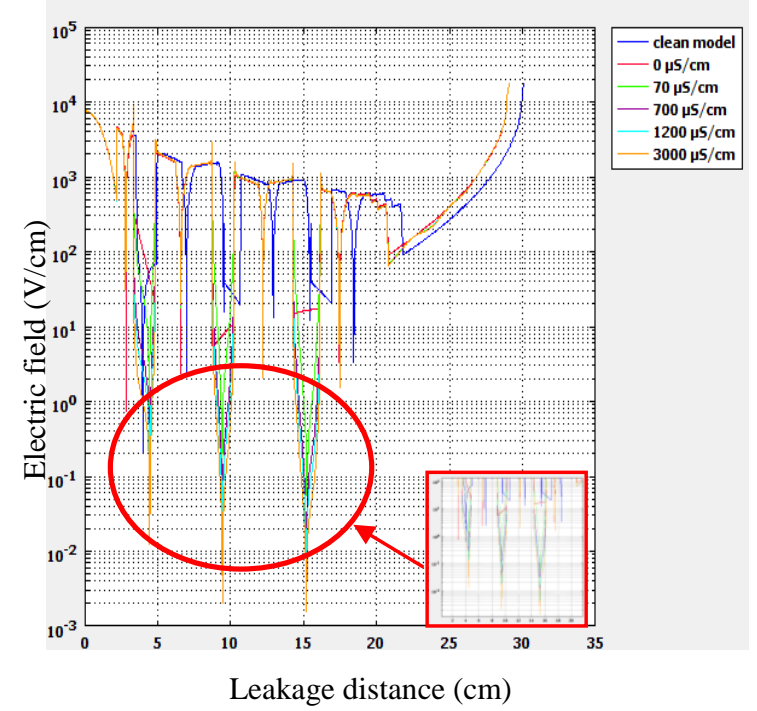

(b) Logarithmic scale

Fig. 11. Electric field-leakage distance for different conductivity

(a) Simple scale (b) Logarithmic scale

Otherwise, figure 12 shows that the conductivities have no incidence on the electric field distribution. We find that the conductivity has practically no effect on the distribution of the electric field.

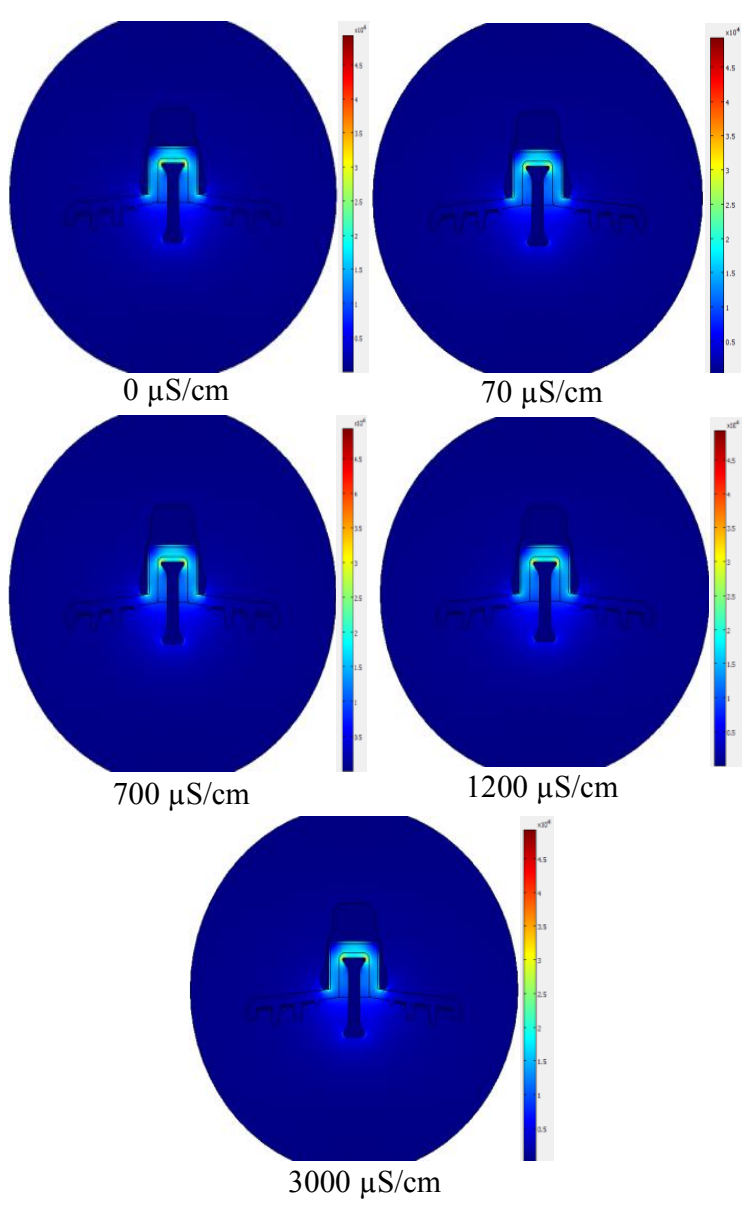

Fig. 12. Electric field distribution for different conductivities 


\subsubsection{Influence of the applied voltage of the line}

For a clean model, we present in figure 13 electric field along the leakage current distance for different applied voltage (simple and logarithmic scale).Figure 13 shows that depending on the applied voltage, only the values of the electric field changes, the shape remains the same.The increase of the applied voltage of the line increases the intensity of the electric field (figure13 (a)). Also, the insulator becomes less rigid, Indeed in the experiment, the increase in the applied voltage causes the flashover of the insulator.

We also note that electric field gets maximal values at the extremities of the insulator (cap and pin of the insulator).

Obviously, demonstrated by figure 11 (b), that the electric field never vanishes in the dielectric materials in our case, the material is the glass. However, it gives a very small value, whatever the applied voltage.(see figure 13 (b)).

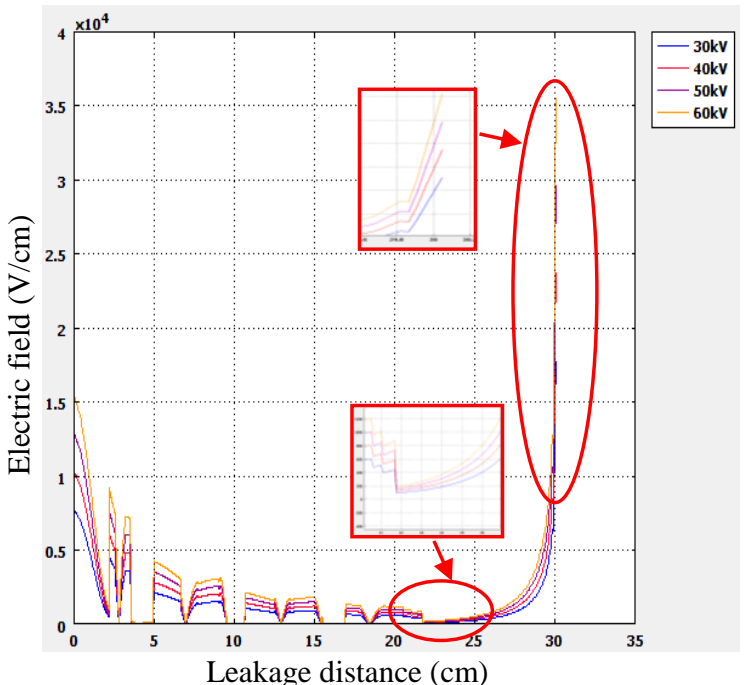

(a) Simple scale

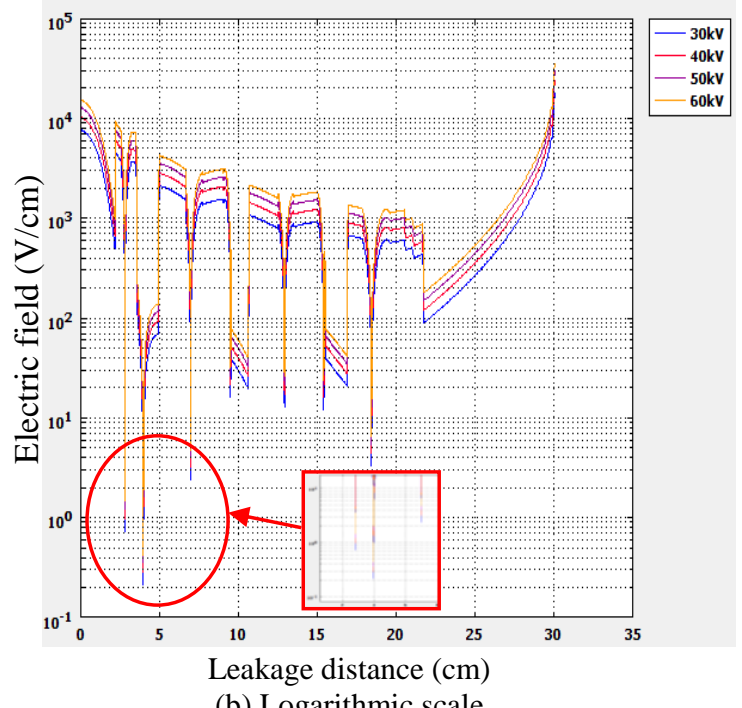

(b) Logarithmic scale

Fig. 13. Electric field-leakage distance for different applied voltage
Figure 14 presents the electric field distribution for different applied voltage of the line, the increase of the applied voltage leads to the increase of the intensity of the electric field.

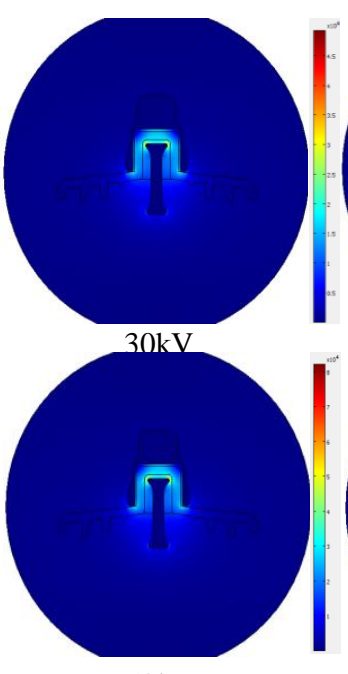

$50 \mathrm{kV}$

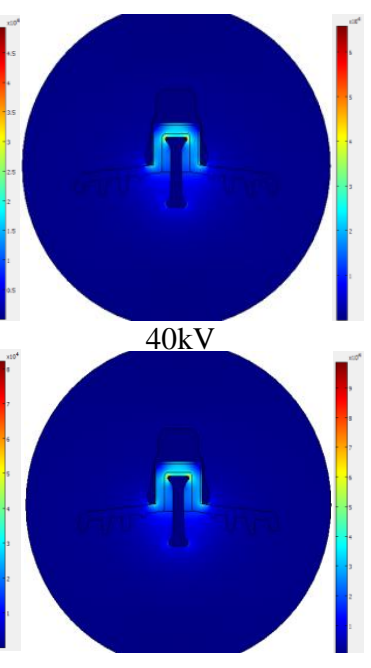

$60 \mathrm{kV}$
Fig. 14. Electric field distribution for different applied voltage

\subsubsection{Influence of the rib width of the insulator}

In this part, we must thoroughly estimate the model with the same radius, and practically the same shape as the real model, but with a better distribution of the field. This leads us to assume that the real model can be improved.

Our proposed system was mentioned previously by figure and table 1 where we cited its characteristics.

We are looking to change the geometry of the real insulator $(1512 \mathrm{~L})$ by changing the length of leakage distance and keeping the same radius (R).

The results of the field thus obtained will be compared with those obtained by the real model. To see the influence of the width of the ribs $\left(\mathrm{x}_{1,2,3,4}\right)$ of the cap and pin insulator. We determine the distribution of the electric field on this insulator model, which is mentioned by figure 15 .

- Real_Model (a) keeping our real dimensions of the cap and pin insulator $1512 \mathrm{~L}$, with a surface of $47.949 \mathrm{~cm}^{2}$.

- Model_01 (c) by increasing the width of the ribs by 1.5 of its actual width, but keeping the same radius $(\mathrm{R})$ as the real model, with a surface of $53.873 \mathrm{~cm}^{2}$.

- Model_02 (b) by decreasing the width of the ribs by 0.5 of its real width, but keeping the same radius $(\mathrm{R})$ as the real model, with a surface of $42.7028 \mathrm{~cm}^{2}$.

- Changes in the real model, are made in a hazardous way in (figure $15 \mathrm{a}, \mathrm{b}, \mathrm{c}$ ), table 4 . 
Table 4. Sizing of proposed HV insulators.

\begin{tabular}{|c|c|c|c|}
\hline Model study & Dimension & Radius, $\mathrm{R}(\mathrm{cm})$ & $\begin{array}{c}\text { Glass surface } \\
\left(\mathrm{cm}^{2}\right)\end{array}$ \\
\hline Real model & $\begin{array}{c}\mathrm{x} " \prime=\mathrm{x}=\left[\mathrm{x}_{1}, \mathrm{x}_{2}, \mathrm{x}_{3}, \mathrm{x}_{4}\right] \\
\text { (fig. } 15 .-\mathrm{a}-)\end{array}$ & 13.1 & 47.949 \\
\hline Model_01 & $\begin{array}{c}\mathrm{x}=1.5 * \mathrm{x}=1.5^{*}\left[\mathrm{x} 1, \mathrm{x}_{2}, \mathrm{x}_{3}, \mathrm{x}_{4}\right] \\
\text { (fig. } 15 .-\mathrm{c}-)\end{array}$ & 13.1 & 53.873 \\
\hline Model_02 & $\begin{array}{c}\mathrm{x} "=0.5^{*} \mathrm{x}=0.5^{*}\left[\mathrm{x}_{1}, \mathrm{x}_{2}, \mathrm{x}_{3}, \mathrm{x}_{4}\right] \\
\text { (fig. } 15 .-\mathrm{b}-)\end{array}$ & 13.1 & 42.7028 \\
\hline
\end{tabular}

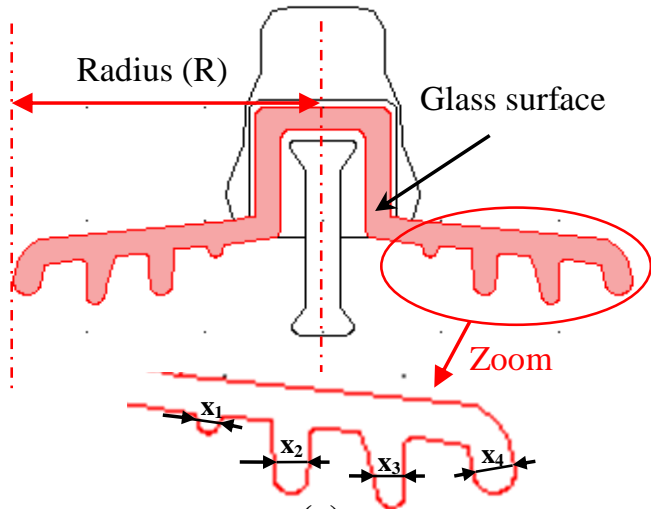

(a)

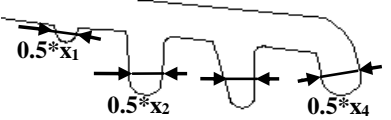

(b)

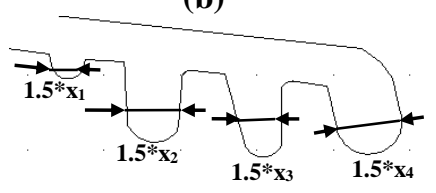

(c)

Fig. 15. Dimensioning of the ribs of the insulator $1512 \mathrm{~L}$

(a)Real Model, (b) Model_02, (c) Model_01

Figure 16 ((a) simple scale, (b) logarithmic scale), shows respectively the distribution of the normal tangential component of the electric field on the insulator on the leakage distance for the three cases studied (real model, model_01, model_02), for the models indicated in table 4 . We apply a voltage of $30 \mathrm{kV}$ in the case of the insulator.

The results cited above demonstrate the importance and the influence of the geometric shape of the insulator on its dielectric behavior.

We notice that the electric field fluctuates between the cap and the pin of the insulator. It presents several local maximums. These local fluctuations and local maximums explain the appearance of localized arcs on the surface of the insulator.

We also note that the distribution of the field on the leakage distance follows the same variations of the real model with a spatial shift due to difference of the leakage distance lengths.

In general, the shape (form) of the field distribution is similar for all models studied.
From the results carried out, the real model is the model that optimizes, the value of the electric field to the cap of the real insulator. It is optimal compared with the other two models.

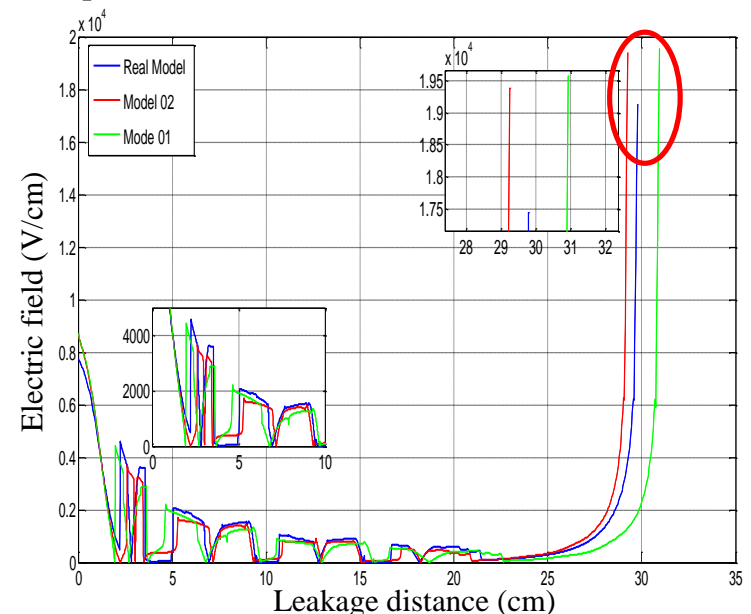

(a) Simple scale

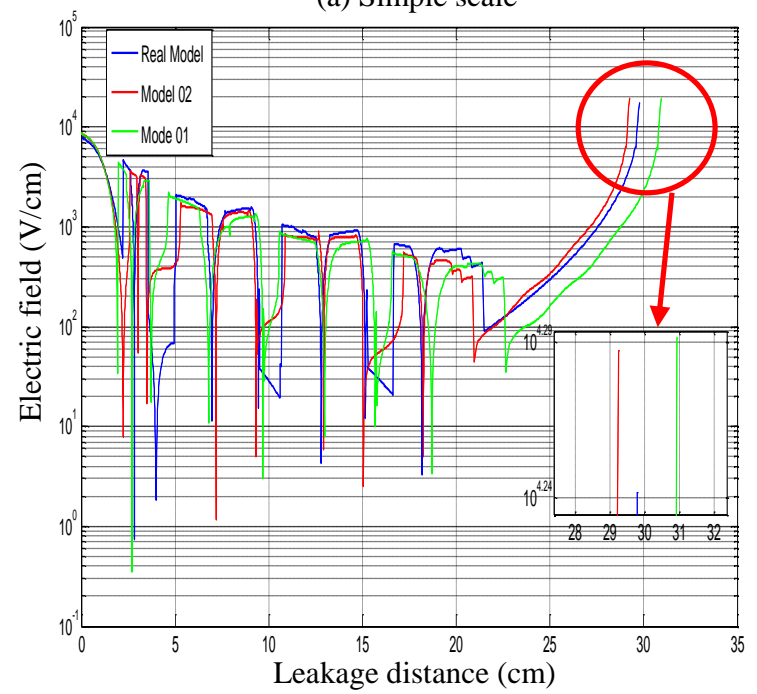

(b) Logarithmic scale

Fig. 16. Electric field-leakage distance for three studied cases (real model, model_01, model_02).

(a)Simple scale, (b)Logarithmic scale

\section{CONCLUSION}

In summary, we have studied the electric field and electric potential distribution artificially polluted of cap and pin insulator (1512L) largely used by Algerian Society for Electricity and Gas (SONELGAZ). This study was conducted using 
COMSOL multiphysics-based on the finite element method (FEM), for different electro-geometric parameters such as the influence of conductivity and applied voltage of the line under AC voltage.

The surface state which affects the distribution of the potential and the electric field and not the conductivity of the pollution. Indeed, the potential distribution is practically equitable since all the elements of the insulator will receive a very close potential difference. Moreover, the parts near the active electrode are most exposed to the electric constraints, namely, the potential difference and the electric field. The metal parts of the insulator, in this case, the cap and the pin, are equipotential and the value of the potential is always fixed. We also noted that potential and the electric field increase with the applied voltage. However, the form of the electric field and potential remain the same. In other words, the difference is in the magnitudes and not in the form. We have noted that the potential and the electric field increase augmentation in applied voltage amplitude.

The maximum value of the electric field is obtained when the insulator is polluted (3000 $\mu \mathrm{S} / \mathrm{cm})$. On the other hand, the effect of the surface state and the conductivity of the pollution is very negligible on the potential distribution. The performance study of a real insulator has the advantage of taking into account all the complexity of the real model for a good analysis of the physical phenomena.

The modification of the geometric shape (form reduction) of the insulator generates an increase in the electric field, then a reduction of the flashover voltage.

Finally, this by this work, the effectiveness of Comsol Multiphysics to calculate the electric field, and potential distribution of electrostatics problems have been proved.

\section{REFERENCES}

1. Bessedik SA, Hadi H. Dynamic arc model of the flashover of the polluted insulators. IEEE Conference on Electrical Insulation and Dielectric Phenomena. CEIDP. Cancun, Mexico 2011;:550-554. DOI: 10.1109/CEIDP.2011.6232716

2. Benguesmia H, M'ziou N, Boubakeur A. Study of the pollution effect on the high voltage of the cap and pin (1512L) insulator using Comsol multiphysics. The International Conference on Mechanics and Energy, (ICME2016-114), Hammamet, Tunisia, 22-24 December 2016.

3. Suflis SA, Gonos IF, Topalis FV, Stathopulos IA. Study of the dielectric behaviour of non-uniformly polluted insulators. XIII International symposium on high voltage engineering, Netherlands 2003; 1-4.

4. Terrab H, Bayadi A. Experimental study using design of experiment of pollution layer effect on insulator performance taking into account the presence of dry bands. IEEE Transactions on Dielectrics and Electrical Insulation
2014; 21(6):2486 - 2495

DOI: 10.1109/TDEI.2014.004542

5. Benguesmia H, M'ziou N, Boubakeur A. AC Flashover: An Analysis with Influence of the Pollution, Potential and Electric Field Distribution on High Voltage Insulator. International Conference Multiphysics Simulation for Systems Design, Sousse Tunisia, 17-19 December 2014;:269-279. DOI: 10.1007/978-3-319-14532-7

6. Gencoglu MT, Cebeci M. Computation of AC flashover voltage of polluted $\mathrm{HV}$ insulators using a dynamic arc model. European Transactions On Electrical Power, 2009; 19(5):689-701. DOI: $10.1002 /$ etep. 249

7. Sunitha NS, Ravi KN, Prakash R, Pushpanjali. A study on leakage current characteristics of polymeric insulator for diffrent pollution layers. International Conference on Power and Advanced Control Engineering (ICPACE) 2015;:383-387. DOI: 10.1109/ICPACE.2015.7274977

8. Mei H, Wang L, Guan Z. Influence of sugar as a contaminant on outdoor insulation characteristics of insulators in a substation. IEEE Transactions on Dielectrics and Electrical Insulation 2012; 19(4):1318-1324. DOI: 10.1109/TDEI.2012.6260007

9. Houlgate RG, Lambeth PJ, Roberts WJ. The performance of insulators at extra and ultra high voltage in a coastal environment. International conference on large high voltage electric systems, CIGRE, report, Paris 1978;:33-01 http://www.e-cigre.org/Order/select.asp?ID=6329

10. Keller-Jacobsen J, Pedersen AA, Rasmussen JK, Henriksen A, Lindqvist C, Smedsfelt S. Field and laboratory tests for the proper dimensioning of insulators exposed to salt pollution. International conference on large high voltage electric systems, CIGRE, report, Paris 1978;:33-11. http://www.e-cigre.org/Order/select.asp?ID=6669

11. El-Koshairy M.A.B, El-Arabaty A.M, EL-Sayed, Aly A.H, Mansour E.A.A, Abdullah A.E, El-Debeiky S. The performance of high voltage transmission lines epoxy resin insulators under desert pollution conditions. International conference on large high voltage electric systems, CIGRE, report, Paris $1978 ;: 15-12$.

http://www.e-cigre.org/Order/select.asp?ID=6597

12. El-Arabaty A, Nosseir A.R, El Debeiky S, Nasser E, El-Sarky A. Selection of insulators suitable for operation in contaminated environments with reference to desert conditions. International conference on large high voltage electric systems, CIGRE, report, Paris 1980;: 33-11.

http://www.e-cigre.org/Order/select.asp?ID=6510

13. El-koshairy MAB, Khalifa MM, Nosseir AR, Elsharkawi E, Awad MM, Zarzoura HEM. Pollution performance of high voltage insulator strings in a desert environment. International conference on large high voltage electric systems, CIGRE, report, Paris 1982;: 33-09.

http://www.e-cigre.org/Order/select.asp?ID=6337

14. Pel-Zhong H, Cheng-Dong X. The tests and investigations on naturally polluted insulators and their application to insulation design for polluted areas. International conference on large high voltage electric system, CIGRE, report, Paris 1982;:33-07. http://www.e-cigre.org/Order/select.asp?ID=6335

15. Aydogmus Z, Cebeci M. A new flashover dynamic model of polluted HV insulators. IEEE Transactions 
on Dielectrics and Electrical Insulation 2004; 11(4):577-584. DOI: 10.1109/TDEI.2004.1324347

16. Bessedik S.A. Contournement des isolateurs pollués. $\mathrm{Ph} . \mathrm{D}$. thesis in Sciences, Department of Electrical Engineering, University of oran,Oran, Algeria, 28 juin 2015.

17. Rasalonjanahary J, Krahenbuhl L, Nicolas A. Computation of electric fields and potential on polluted insulators using a boundary element method. IEEE Transportation On Magnetics 1992; 28(2):1473-1476. DOI: 10.1109/20.123974

18. Hartings R. Electric fields along a post insulator: Acmeasurements and calculations. IEEE Transactions on Power Delivery 1994; 9(2):912-918. DOI: $10.1109 / 61.296274$

19. El-Kishky H, Gorur R. Electric potential and field computation along AC HV insulators. IEEE Transactions on Dielectrics and Electrical Insulation 1994;1(6):982-990. DOI: 10.1109/94.368665

20. Volat C, Farzaneh M. Three-dimensional modeling of potential and electric-field distributions along an EHV ceramic post insulator covered with ice-part $\mathrm{i}$ :simulations of a melting period. IEEE Transactions on Power Delivery 2013; 20(3):2006-2013. DOI: 10.1109/TPWRD.2005.848460

21. Andrew J. Electric fields on AC composite transmission line insulators. IEEE Transactions on Power Delivery 2008; 23(2):823-830. DOI: $10.1109 /$ TPWRD.2007.911127

22. M'hamdi B, Teguar M, Mekhaldi A. Potential and Electric Field Distributions on HV Insulators String Used in The $400 \mathrm{kV}$ Novel Transmission Line in Algeria. IEEE International Conference on Solid Dielectrics, (ICSD), Bologna, Italy June30-July4, 2013;190-193. DOI: 10.1109/ICSD.2013.6619653

23. Sima W, Yang Q, Sun C, Guo F. Potential and electric-field calculation along an ice-covered composite insulator with finite-element method. IEE Proceedings-generation Transmission and Distribution 2006; 153(3):343-349. DOI: 10.1049/ipgtd:20050227

24. Arora R, Mosch W. High voltage insulation engineering. Wiley-IEEE press series on power engineering. First Edition. Institute of Electrical and Electronics Engineers. Published by John Wiley \& Sons, Inc. 2011.

http://onlinelibrary.wiley.com/doi/10.1002/97804709 47906.fmatter/pdf

25. Guan Z, Wang L, Yang B, Liang X, Li Z. Electric field analysis of water drop corona. IEEE Transactions on power delivery 2005; 20(2):964-969. DOI: 10.1109/TPWRD.2004.837672

26. Gu Y, Li J. Finite element analysis of the instep fatigue trauma in the high-heeled gait. World Journal of Modelling and Simulation 2005; 1(2):117-122.

27. Liu Y, Yu C, Sun X, Wang J. 3d fe model reconstruction and numerical simulation of airflow for the upper airway. World Journal of Modelling and Simulation 2006; 2(3):190-195.

28. Meeker D. Finite Element Method Magnetics. User's Manual, Version 4.2; 2006.

29. Muniraj C, Chandrasekar S. Finite Element Modeling for Electric Field and Voltage Distribution along the Polluted Polymeric Insulator. World Journal of Modelling and Simulation 2012; 8(4):310-320.

30. Nicolopoulou EP, Gralista EN, Kontargyri VT, Gonos IF, Stathopulos IA. Electric field and voltage distribution around composite insulators. XVII
International Symposium on High Voltage Engineering, August 22-26, Hannover, Germany 2011.

31. M'hamdi B. Amélioration des performances des chaînes d'isolateurs de haute tension. Ph.D. thesis in Sciences, Department of Electrical Engineering, Ecole Nationale Polytechnique, Algiers, Algeria, 14 December 2016.

32. M'ziou N, Bengasmia $\mathrm{H}$, Guia $\mathrm{T}$. Influence of the Pollution on the Flashover of High Voltage Insulator. Word Academy of Science Engineering and Technology, Dubai, January 2012, (61):1595-1597.

33. Benguesmia H, M'ziou N, Boubakeur A. Influence de la Pollution Discontinue sur la Tension de Contournement d'un Isolateur de Haute Tension. 7th International Conference on Electrical Engineering, Batna, Alegria, 8- 10 October 2012: 556-558.

34. Benguesmia H, M'ziou N, Boubakeur A. Influence de la Pollution sur le Contournement d'un Isolateur de Haute Tension. The International Conference on Electronics \& Oil: from Theory to Applications, Ouargla, Algeria, proceeding, March 2013: 51.

35. Benguesmia H, M'ziou N, Chouchou A M, Rachdi L. Experimental Study of the various pollution and simulation of potential and electric field distribution using FEMM at a high voltage insulator under alternative current. International Symposium on Computational and Experimental Investigations of Fluid and Structure Dynamics, (CEFSD2015-94), Hammamet, Tunisia, 16-18 March 2015:144.

\section{Received 2017-11-21}

Accepted 2018-03-09

Available online 2018-03-12

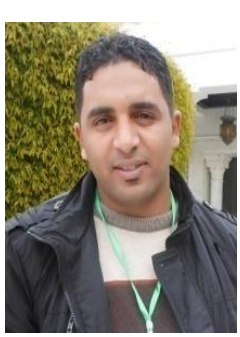

Hani BENGUESMIA was born in Bou-saada, M'sila, Algeria. He received the M.Sc. degrees in Electrical Engineering from Mohamed kheider University, Biskra, Algeria, in 2012. He has been working for more than five years with the Department of Electrical Engineering, University of M'sila, as a Professor. His main research interests include high voltage, outdoor insulation, numerical modeling and simulation. He is the author or co-author of several technical papers.

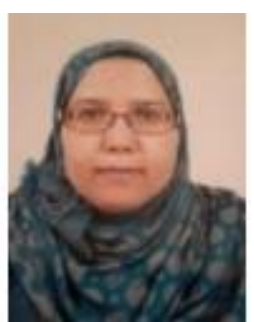

Nassima M'ZIOU was born in Biskra-Algeria. She received the engineer and Magister degrees in Electrical engineering from Biskra University and Batna University, Algeria, in 1997 and 2001, respectively, and doctorate degree in electrical engineering from the National Polytechnic School of Algiers, Algeria, in 2009. Her main research interests include high voltage, Modeling the electromagnetic radiation, outdoor insulation, numerical modeling and simulation. She is the author or co-author of several technical papers. 


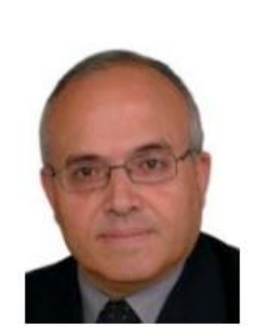

Ahmed BOUBAKEUR was born in Biskra, Algeria in 1952. He received in 1975 the degree of Engineer in electrical engineering from Ecole Nationale Polytechnique (ENP) of Algiers, and in 1979 he obtained the Doctorate in Technical Sciences from the Institute of High Voltage Engineering of the Technical University of Warsaw of in Poland. $\mathrm{He}$ is currently a professor at ENP of Algiers where he has been giving lectures and supervising research in the field of High Voltage Engineering since 1982. His principal research areas are discharge phenomena, insulators pollution, lightning, polymeric cables insulation, transformer oil ageing, neural network and fuzzy logic application in HV insulation diagnosis, and electric field calculation and measurement. He is IEEE senior member, member of the Algerian HV Power Systems Association ARELEC (National Algerian Commity of CIGRE and ENP Elders Association ADEP. 